\title{
Clinical Trial Team Documentation
}

National Cancer Institute

\section{Source}

National Cancer Institute. Clinical Trial Team Documentation. NCI Thesaurus. Code C115617.

Records pertaining to a group of healthcare and academic professionals working together on a clinical trial. 